\title{
An Adaptive Nonlinear Extended State Observer for the Sensorless Speed Control of a PMSM
}

\author{
Minggang Gan ${ }^{1,2}$ and Chenyi Wang ${ }^{1,2}$ \\ ${ }^{1}$ School of Automation, Beijing Institute of Technology, Beijing 100081, China \\ ${ }^{2}$ Key Laboratory of Intelligent Control and Decision of Complex Systems, Beijing 100081, China \\ Correspondence should be addressed to Chenyi Wang; chimes298@163.com
}

Received 13 December 2014; Accepted 5 March 2015

Academic Editor: Andrzej Swierniak

Copyright (c) 2015 M. Gan and C. Wang. This is an open access article distributed under the Creative Commons Attribution License, which permits unrestricted use, distribution, and reproduction in any medium, provided the original work is properly cited.

\begin{abstract}
This paper presents a sensorless speed control strategy for a permanent-magnet synchronous motor (PMSM) based on an adaptive nonlinear extended state observer (ANLESO). In this paper, an extended state observer (ESO), which takes back-EMF (back electromotive force) as an extended state, is used to estimate the rotor position and the rotor speed because of its simpler structure and higher accuracy. Both linear ESO (LESO) and nonlinear ESO (NLESO) are considered to estimate the back-EMF of PMSM, and NLESO is finally implemented due to its obvious advantage in convergence. The convergence characteristics of the estimation error of the observer are analyzed by the Lyapunov theory. In order to take both stability and steady-state error into consideration, an adaptive NLESO is proposed, which adaptively adjusts the parameters of NLESO to a compromised value. The performance of the proposed method was demonstrated by simulations and experiments.
\end{abstract}

\section{Introduction}

In recent years, permanent-magnet synchronous motors have increasingly gained lots of applications due to their high efficiency, high dynamic response, and high torque to current ratio $[1,2]$. Compared to DC motors, PMSMs are superior in robustness and overload capability and they do not need mechanical commutation. As the fast switch components and digital signal processors become economical, PMSMs are widely used as an alternative for energy saving applications. Besides, some countries have kept using low-cost induction motors due to their simple structure and easiness in manufacturing. However, induction motors are less efficient than PMSMs in terms of performance [3, 4].

PMSM drives require a position sensor with high resolution to achieve an efficient vector control, such as a shaft encoder or a resolver. Unfortunately, these sensors are expensive and have a limited lifetime. Besides, the size of the motor assembly will become larger. Therefore, many sensorless control methods have been developed to eliminate these mechanical sensors. In particular in some extreme environments where position sensors may work abnormally, sensorless control methods are more robust than those using position sensors [4].

By means of injecting high frequency signal into motor, the impedance difference caused by magnetic saturation, which contains the information about the rotor position, can be calculated [5]. However, injecting high frequency signal brings noise and torque ripples. Because of good standstill performance, the method is usually used within low-speed range [6,7]. The extended Kalman filter (EKF) was also employed for rotor speed and position estimation due to its good dynamic performance and strong antijamming capability [8]. Algorithm complexity and large calculating quantity are disadvantages of EKF, which limits its practical application. Neural network technology has a good advantage in terms of parameter identification and it has been used in sensorless control system by many scholars [9]. In these papers, the rotor position is identified online by neural network. However, the method needs a long computation time and brings great burden on the digital signal processing, which gives rise to choke points in applications. Zhang and $\mathrm{Li}$ proposed the model reference adaptive scheme (MRAS) to implement a sensorless control system. The idea of MRAS 
is to build a reference model of the PMSM system without containing unknown parameters and to obtain the difference between the reference model outputs and actual system outputs. Next, an appropriate adaptive law will be designed to adjust parameters of reference model in real time according to the difference [10]. But the accuracy of this method depends on the designed reference model, which may prohibit the convergence of the system. Moreover, in [11, 12], the flux linkage is used as state variable and is estimated directly. Some authors used a sliding mode observer (SMO) approach $[6,13-$ 16]. The structure of SMO is simple and convenient to be used in practical applications. Unfortunately, the estimation accuracy of SMO would be affected by chattering.

The extended state observer (ESO) first proposed by Huang and Han in [17] is the key step of the active disturbance rejection control (ADRC) that is taking off as a technology after numerous successful applications in engineering. ESO has simple structure and it is able to estimate unmodeled dynamics accurately in many cases. In terms of ADRC, a class of nonlinear ESOs is designed to estimate the sum of both the states and external disturbances [18]. After that, Gao proposed a class of linear ESOs (LESO) and provided guidance on how to choose the optimal parameters in the controller design. In this way, the number of parameters to be configured is reduced [19]. At present, ESO is mainly used in control system to estimate disturbances and to compensate them via a feed-forward cancellation technique [20-22]. Besides, ESO can be extended to multi-input-multi-output systems as well [22].

In this paper, a sensorless speed control scheme for a PMSM based on an ANLESO is proposed. ESO is applied to estimate the rotor position and rotor speed of PMSM for the first time. The information of the rotor position and the rotor speed of PMSM can be calculated by estimating the back-EMF. For this reason, the estimation accuracy of backEMF affects the accuracy of the position and speed directly. ESO usually treats all the external disturbances and/or system uncertainties as the "total disturbance" and extends it as an additional state variable [16]. Therefore, system states and unknown parts of system can be estimated by ESO in the meantime without knowing the model of the unknown parts (the derivative of the unknown parts). In this scheme, backEMF is the unknown part of the system and it would be treated as an additional state variable to be estimated. BackEMF contains the information of the rotor position and speed that cannot be obtained without sensor. For this reason, backEMF cannot be modeled directly. As mentioned previously, ESO would treat back-EMF as "disturbance" and estimate the back-EMF accurately without knowing its model. By means of Lyapunov stability analysis, an adaptive control scheme is adopted to balance stability and steady-state error. The adaptive control scheme could adaptively adjust the parameters of ESO to a compromised value, and the steady-state error will converge to a minimum on the premise of system stable. Compared to other sensorless control methods, ANLESO has simpler structure, smaller chattering, and higher accuracy.

The state equations of the stator current in a stator-fixed reference frame and the back-EMF for each phase in the fixed frame of the PMSM are discussed in Section 2. In Section 3, an adaptive nonlinear extended state observer for the sensorless control scheme is designed and discussed. Section 4 gives the simulation results and Experimental results. Finally, conclusions and suggestions for future improvements are given in Section 5.

\section{Mathematical Model}

The voltages in the three phases can be transformed into the synchronous coordinates in the two phases for vector control. The state equations of the stator current, written in a statorfixed reference frame $(\alpha \beta)$, take the following form [23]:

$$
\begin{aligned}
& \frac{d i_{\alpha}}{d t}=-\frac{R}{L} i_{\alpha}-\frac{1}{L} e_{\alpha}+\frac{1}{L} V_{\alpha}, \\
& \frac{d i_{\beta}}{d t}=-\frac{R}{L} i_{\beta}-\frac{1}{L} e_{\beta}+\frac{1}{L} V_{\beta},
\end{aligned}
$$

where $i_{\alpha, \beta}, e_{\alpha, \beta}$, and $V_{\alpha, \beta}$ represent the current, electromotive force, and voltage for each phase, respectively. $R$ and $L$ represent the stator resistance and inductance, respectively.

The back EMF for each phase can be represented in the fixed frame as

$$
\begin{aligned}
& e_{\alpha}=-K_{E} \omega_{r} \sin \theta, \\
& e_{\beta}=K_{E} \omega_{r} \cos \theta,
\end{aligned}
$$

where $K_{E}, \omega_{r}$, and $\theta$ represent the magnetic flux of the PM, the electric angular velocity, and the rotor angle, respectively.

\section{Proposed Adaptive Nonlinear ESO}

In the sensorless control system, the back-EMF $e_{\alpha}, e_{\beta}$ are usually figured out by the information of control signals $V_{\alpha}$, $V_{\beta}$ and output currents $i_{\alpha}, i_{\beta}$. In other words, from the system formulated by (1) and (2), $e_{\alpha}$ and $e_{\beta}$ can be treated as the unknown parts of the system. Thus, the back-EMF would be extended as additional state variables. In this section, linear ESO and nonlinear ESO are described, respectively. For LESO, the bounded-input bounded-output (BIBO) stability can be reached. For NLESO, a Lyapunov stability analysis is shown. At last, an adaptive control scheme is designed in order to improve the estimated accuracy.

The block diagram of the sensorless control system for PMSM is shown in Figure 1. The space vector pulse width modulation (SVPWM) algorithm is used as modulation strategy to generate a sinusoidal current of the stator. To control the PMSM, the three-phase coordinates need to be transformed into $d q$ synchronous coordinates by Clarke transformation and Park transformation. An ADC (analog to digital converter) module is used to detect phase current and bus voltage. The proportional-integral (PI) control is used in speed loop and current loop. All the sensorless control algorithms are simulated by MatLab and executed on a DSP chip.

3.1. Linear ESO. Note that this system is symmetric, and we only need to design an observer to estimate $e_{\alpha}$ (the structure 


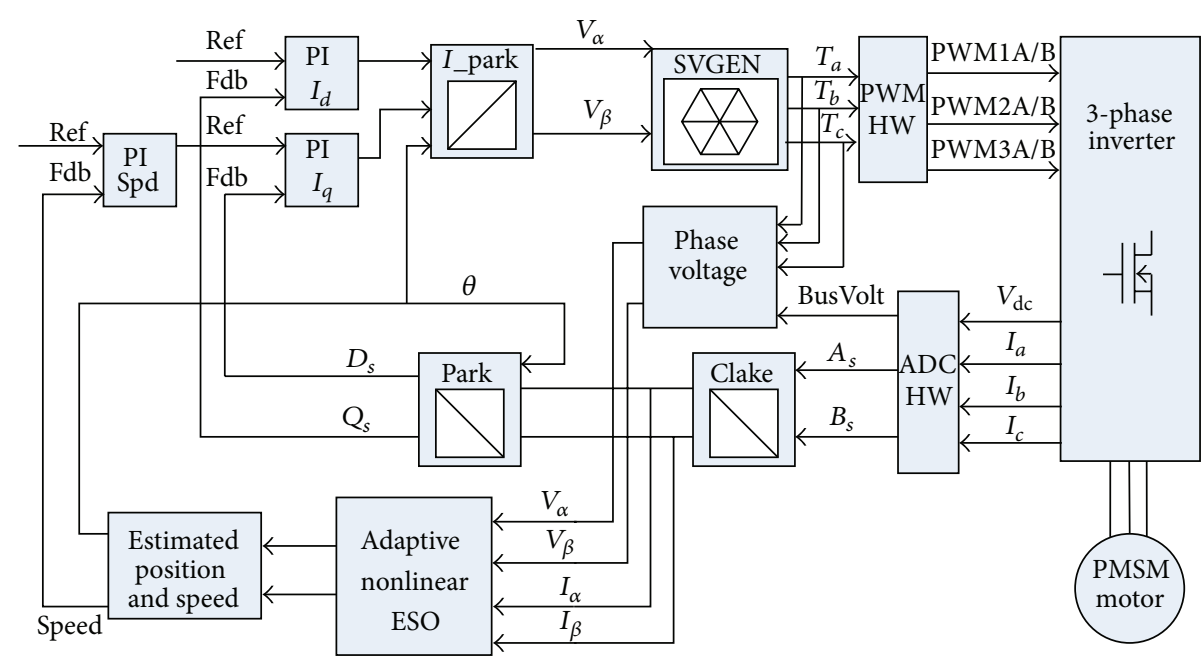

FIGURE 1: Block diagram of the sensorless vector control of PMSM.

and parameters of the observer). In this way, the order of the observer can be reduced.

Set $x_{1}=i_{\alpha}$ and $x_{2}=-e_{\alpha}$ as augmented states. $h$ is the derivative of $x_{2}$, which is a variable that we do not need to know. The state equation (1) is written in the following form:

$$
\begin{aligned}
& \dot{x}_{1}=-\frac{R}{L} x_{1}+\frac{1}{L} x_{2}+\frac{1}{L} u_{1}, \\
& \dot{x}_{2}=h .
\end{aligned}
$$

The output can be written as

$$
y=M\left[\begin{array}{l}
x_{1} \\
x_{2}
\end{array}\right]
$$

where $M=\left[\begin{array}{ll}1 & 0\end{array}\right]$.

Now $x_{2}=-e_{\alpha}$ can be estimated using a linear extended state observer as follows:

$$
\left[\begin{array}{l}
\dot{z}_{1} \\
\dot{z}_{2}
\end{array}\right]=\left[\begin{array}{cc}
-\frac{R}{L} & \frac{1}{L} \\
0 & 0
\end{array}\right]\left[\begin{array}{l}
z_{1} \\
z_{2}
\end{array}\right]+\left[\begin{array}{c}
\frac{1}{L} \\
0
\end{array}\right] u+G\left(y-z_{1}\right),
$$

where $z_{1}$ and $z_{2}$ are used to estimate the value of $x_{1}$ and $x_{2}$, respectively. $G=\left[\begin{array}{ll}-\beta_{1} & -\beta_{2}\end{array}\right]^{T}$ is the observer gain vector, which can be obtained using any known method, for example, the pole placement technique.

Let $e=\left[\begin{array}{l}x_{1}-z_{1} \\ x_{2}-z_{2}\end{array}\right]$; then the error equation can be written as

$$
\dot{e}=\left(A_{o}-G M\right) e+H,
$$

where

$$
A_{o}=\left[\begin{array}{cc}
-\frac{R}{L} & \frac{1}{L} \\
0 & 0
\end{array}\right], \quad H=\left[\begin{array}{ll}
0 & h
\end{array}\right]^{T} .
$$

Obviously, the LESO is bounded-input bounded-output (BIBO) stable if $\left(A_{o}-G C\right)$ is stable and $h$ is bounded [19].
3.2. Nonlinear ESO. For the sake of reducing the steady-state error, a nonlinear extended state observer is proposed as follows:

$$
\begin{aligned}
& {\left[\begin{array}{l}
\dot{z}_{1} \\
\dot{z}_{2}
\end{array}\right]=\left[\begin{array}{cc}
-\frac{R}{L} & \frac{1}{L} \\
0 & 0
\end{array}\right]\left[\begin{array}{l}
z_{1} \\
z_{2}
\end{array}\right]+\left[\begin{array}{l}
\frac{1}{L} \\
0
\end{array}\right] u} \\
& +\left[\begin{array}{c}
-\beta_{1} \cdot e_{1} \\
-\beta_{2} \cdot\left|e_{1}\right|^{1 / 2} \cdot \operatorname{sign}\left(e_{1}\right)
\end{array}\right] \text {. }
\end{aligned}
$$

Let $e=\left[\begin{array}{c}x_{1}-z_{1} \\ x_{2}-z_{2}\end{array}\right]$; then the error equation can be written as

$$
\begin{aligned}
& \dot{e}_{1}=-\left(\frac{R}{L}+\beta_{1}\right) e_{1}+\frac{1}{L} e_{2}, \\
& \dot{e}_{2}=-h-\beta_{2}\left|e_{1}\right|^{1 / 2} \operatorname{sign}\left(e_{1}\right) .
\end{aligned}
$$

When the steady state is reached, we can obtain

$$
\begin{aligned}
- & h-\beta_{2}\left|e_{1}\right|^{1 / 2} \operatorname{sign}\left(e_{1}\right) \\
= & -\left(\frac{R}{L}+\beta_{1}\right) e_{1}+\frac{1}{L} e_{2}=0 .
\end{aligned}
$$

Hence, the steady-state errors are

$$
\begin{aligned}
& e_{1}=\left(\frac{h}{\beta_{2}}\right)^{2}, \\
& e_{2}=\left(R+L \beta_{1}\right)\left(\frac{h}{\beta_{2}}\right)^{2} .
\end{aligned}
$$

Theorem 1. For system (4), the state error of the nonlinear extended state observer (9) converges asymptotically if the following conditions are satisfied:

(C1) $\left(R / L+\beta_{1}\right)>0$

(C2) $\beta_{2}>0$. 
Proof. The goal is to prove that there exists a positive definite energy function whose derivative is always made negative. The following energy function is chosen [24]:

$$
\begin{aligned}
V & \left(e_{1}, e_{2}\right) \\
& =A\left|e_{1}\right|^{3 / 2}-B e_{1} e_{2}+C e_{2}^{2} \\
& =A\left|e_{1}\right|^{-1 / 2}\left[\left(e_{1}-\frac{B\left|e_{1}\right|^{1 / 2}}{2 A} e_{2}\right)^{2}-\frac{B^{2}\left|e_{1}\right|}{4 A^{2}} e_{2}^{2}\right]+C e_{2}^{2} \\
& =A\left|e_{1}\right|^{-1 / 2}\left(e_{1}-\frac{B\left|e_{1}\right|^{1 / 2}}{2 A} e_{2}\right)^{2}+\left(C-\frac{B^{2}\left|e_{1}\right|^{1 / 2}}{4 A}\right) e_{2}^{2},
\end{aligned}
$$

where $A, B$, and $C$ are the parameters to be determined. Suitable $A, B$, and $C$ need to be chosen to let the energy function meet the Lyapunov stability theorem.

In order to guarantee that $V\left(e_{1}, e_{2}\right)$ is positively definite, the following rules need to be followed:

(R1) $A>0$

(R2) $C>B^{2}\left|e_{1}\right|^{1 / 2} / 4 A>0$.

Since $\left|e_{1}\right|^{1 / 2}$ is bounded, (R2) always can be satisfied by choosing a suitable $C$.

Calculate the partial derivative of $V\left(e_{1}, e_{2}\right)$ as follows:

$$
\begin{aligned}
& \frac{\partial V}{\partial e_{1}}=\frac{3}{2} A\left|e_{1}\right|^{1 / 2} \operatorname{sign}\left(e_{1}\right)-B e_{2}, \\
& \frac{\partial V}{\partial e_{2}}=-B e_{1}+2 C e_{2} .
\end{aligned}
$$

The derivative of the energy function is as follows:

$$
\dot{V}=\frac{\partial V}{\partial e_{1}} \dot{e}_{1}+\frac{\partial V}{\partial e_{2}} \dot{e}_{2}
$$

By substituting (15) into (16), $\dot{V}$ can be given as

$$
\begin{aligned}
\dot{V}= & \left(\frac{3}{2} A\left|e_{1}\right|^{1 / 2} \operatorname{sign}\left(e_{1}\right)-B e_{2}\right)\left(-\left(\frac{R}{L}+\beta_{1}\right) e_{1}+\frac{1}{L} e_{2}\right) \\
& +\left(-B e_{1}+2 C e_{2}\right)\left(-h-\beta_{2}\left|e_{1}\right|^{1 / 2} \operatorname{sign}\left(e_{1}\right)\right) .
\end{aligned}
$$

From (17), the following expression can be deduced:

$$
\begin{aligned}
\dot{V}= & \left(\frac{3}{2} \frac{A}{L}-2 C \beta_{2}+B\left(\frac{R}{L}+\beta_{1}\right)\left|e_{1}\right|^{1 / 2}\right) \\
& \cdot\left|e_{1}\right|^{-1 / 4}\left|e_{1}\right|^{3 / 4} \operatorname{sign}\left(e_{1}\right) e_{2} \\
& -\frac{B}{L} e_{2}^{2}-\left(\frac{3}{2} A\left(\frac{R}{L}+\beta_{1}\right)-B \beta_{2}\right)\left|e_{1}\right|^{2(3 / 4)} \\
& +\left(B h e_{1}-2 c h e_{2}\right) .
\end{aligned}
$$

Assume that

$$
\begin{aligned}
& X=\frac{3}{2} A\left(\frac{R}{L}+\beta_{1}\right)-B \beta_{2}, \\
& Y=\left(\frac{3}{2} \frac{A}{L}-2 C \beta_{2}+B\left(\frac{R}{L}+\beta_{1}\right)\left|e_{1}\right|^{1 / 2}\right)\left|e_{1}\right|^{-1 / 4}, \\
& Z=\frac{B}{L} .
\end{aligned}
$$

Equation (18) can be rewritten as

$$
\begin{aligned}
\dot{V}= & -X\left|e_{1}\right|^{2(3 / 4)}+Y\left|e_{1}\right|^{3 / 4} \operatorname{sign}\left(e_{1}\right) e_{2} \\
& -Z e_{2}^{2}-\left(- \text { Bhe }_{1}+2 C h e_{2}\right) \\
= & V_{1}-V_{2},
\end{aligned}
$$

where $V_{1}=-X\left|e_{1}\right|^{2(3 / 4)}+Y\left|e_{1}\right|^{3 / 4} \operatorname{sign}\left(e_{1}\right) e_{2}-Z e_{2}^{2}$ is a quadratic function with regard to $\left|e_{1}\right|^{3 / 4} \operatorname{sign}\left(e_{1}\right)$ and $e_{2} \cdot V_{2}=$ $\left(-B h e_{1}+2 C h e_{2}\right)$ is a plane function with regard to $e_{1}$ and $e_{2}$. A necessary and sufficient condition for the positively definite property of the quadratic function $V_{1}$ can be obtained:

$$
\begin{aligned}
& \text { (1) } X>0 \\
& \text { (2) } Z>0 \\
& \text { (3) } Y^{2}-4 X Z<0 \text {. }
\end{aligned}
$$

From (1) we have

(R3) $(3 / 2) A\left(R / L+\beta_{1}\right)>B \beta_{2}$.

From (2) we have

(R4) $B / L>0$, which means $B>0$.

Then, from (3) we can derive that

$$
\begin{aligned}
\left(\frac{3}{2}\right. & \left.\frac{A}{L}-2 C \beta_{2}+B\left(\frac{R}{L}+\beta_{1}\right)\left|e_{1}\right|^{1 / 2}\right)^{2}\left|e_{1}\right|^{-1 / 2} \\
& <4 \frac{B}{L}\left(\frac{3}{2} A\left(\frac{R}{L}+\beta_{1}\right)-B \beta_{2}\right) .
\end{aligned}
$$

Then, the following expression can be obtained

$$
\begin{aligned}
& \left(\frac{3}{2} \frac{A}{L}-2 C \beta_{2}+B\left(\frac{R}{L}+\beta_{1}\right)\left|e_{1}\right|^{1 / 2}\right) \\
& \quad<2 \sqrt{\frac{B}{L}\left(\frac{3}{2} A\left(\frac{R}{L}+\beta_{1}\right)-B \beta_{2}\right)}\left|e_{1}\right|^{1 / 4} .
\end{aligned}
$$

Assume that

$$
\begin{aligned}
& a=B\left(\frac{R}{L}+\beta_{1}\right), \\
& b=\sqrt{\frac{B}{L}\left(\frac{3}{2} A\left(\frac{R}{L}+\beta_{1}\right)-B \beta_{2}\right)}, \\
& c=\frac{3}{2} \frac{A}{L}-2 C \beta_{2}, \\
& x=\left|e_{1}\right|^{1 / 4} .
\end{aligned}
$$


Equation (22) can be rewritten as

$$
c+a x^{2}<2 b x .
$$

It can be verified that there exists some meaningful $x$ satisfying inequation (24) and meeting the rules (R1) (R4) if and only if the following conditions are satisfied:

$$
\left(\frac{R}{L}+\beta_{1}\right)>0, \quad \beta_{2}>0 .
$$

Therefore, $a=B\left(R / L+\beta_{1}\right)>0$, and inequality (24) denotes a parabola going upwards. Due to the existence of some meaningful $x$ satisfying inequality (24), the vertex of the parabola must be negative:

$$
b^{2}-a c>0 \text {. }
$$

Hence,

$$
\begin{gathered}
\frac{B}{L}\left(\frac{3}{2} A\left(\frac{R}{L}+\beta_{1}\right)-B \beta_{2}\right)-B\left(\frac{R}{L}+\beta_{1}\right)\left(\frac{3}{2} \frac{A}{L}-2 C \beta_{2}\right)>0 \\
B \beta_{2}\left(2 C\left(\frac{R}{L}+\beta_{1}\right)-\frac{B}{L}\right)>0 \\
2 C\left(\frac{R}{L}+\beta_{1}\right)>\frac{B}{L} .
\end{gathered}
$$

Inequality (26) is established between the two real roots $x=\left(b \pm \sqrt{b^{2}-a c}\right) / a$ of the quadratic equation $a x^{2}-2 b x+c=$ 0 . In order to separate the two roots as far as possible and make the smaller one very small, a very large $B$ needs to be selected, which makes $B \beta_{2} \gg 0$, and the choice of parameter $C$ is required to ensure $2 C\left(R / L+\beta_{1}\right)-B / L>0$. Finally, choose appropriate $A$ to make parameters $B$ and $C$ satisfy rules $(\mathrm{R} 1) \sim(\mathrm{R} 4)$. In this way, $V_{1}$ will be a negative definite function with variable $e_{1}$ in a very wide range and arbitrary $e_{2}$. Meanwhile, the area in which $\dot{V}=V_{1}-V_{2}$ does not satisfy negative conditions (the area $\dot{V}>0$ ) is the part above the intersecting line of the quadratic function $V_{1}$ and the plane function $V_{2}$.

The value of $e_{1}$ in the intersecting line is the same order as $e_{1}=(B h / X)^{2}$ which is the root of the following equation:

$$
B h e_{1}=X\left|e_{1}\right|^{2(3 / 4)} \text {. }
$$

Since $X$ is the same order as $B \beta_{2}$, the value of $e_{1}$ in the intersecting line is the same order as $\left(h / \beta_{2}\right)^{2}$. Therefore, a large enough $\beta_{2}$ can guarantee that $e_{1}$ is stable in a very wide range. The larger $\beta_{2}$ we set, the smaller the unstable boundary of $e_{1}$, and then it will result in a better convergence.

In the same way, the value of $e_{2}$ in the intersecting line is the same order as $e_{2}=(2 \mathrm{Ch} / \mathrm{Z})$ which is the root of the following equation:

$$
2 C h e_{2}=Z e_{2}^{2} \text {. }
$$

Consider that $Z=B$, the value of $e_{1}$ in the intersecting line is the same order as $(2 C h / B)$. From inequality (21), the inequality $2 C\left(R+L \beta_{1}\right) / B>1$ holds. Therefore, a large enough $\left(R+L \beta_{1}\right)$, by setting $\beta_{1}$, can guarantee the existence of appropriate $B$ and $C$ to make $\left|e_{2}\right|=|(2 C h / B)|$ small enough.

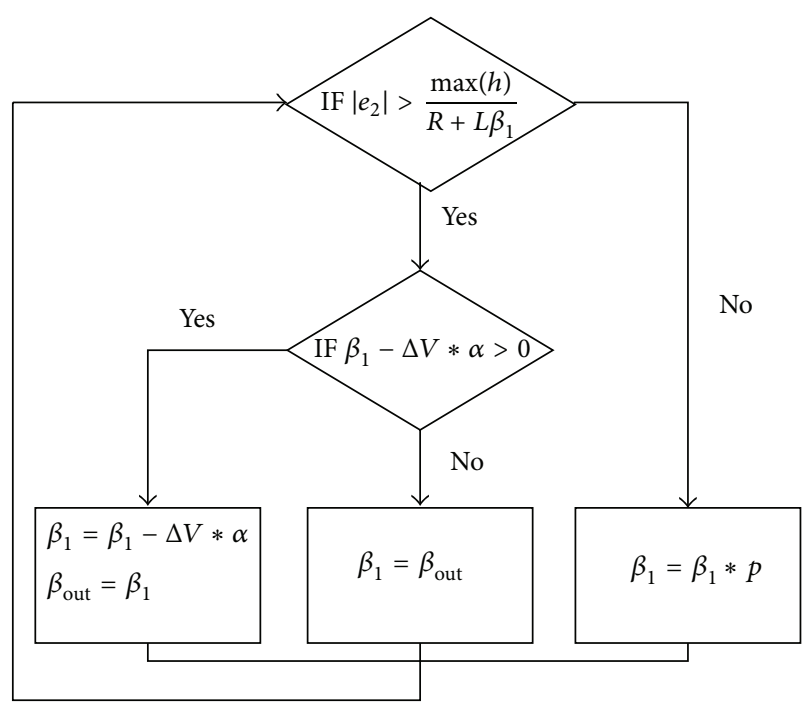

FIGURE 2: Flow chart of the algorithm to calculate $\beta_{1}$.

Remark 1. Obviously, the state error would not actually go to zero but enter, and is contained within, a neighborhood of the origin by this method. Therefore, by means of setting appropriate $\beta_{1}$ and $\beta_{2}$, the performance required in practical engineering can be achieved.

Remark 2. Using a sigmoid function as the nonlinear function in ESO can reduce chatting in the system [15]. Consider

$$
\begin{aligned}
{\left[\begin{array}{c}
\dot{Z}_{1} \\
\dot{Z}_{2}
\end{array}\right]=} & {\left[\begin{array}{cc}
-\frac{R}{L} & \frac{1}{L} \\
0 & 0
\end{array}\right]\left[\begin{array}{c}
Z_{1} \\
Z_{2}
\end{array}\right]+\left[\begin{array}{c}
\frac{1}{L} \\
0
\end{array}\right] u } \\
& +\left[\begin{array}{c}
-\beta_{1} \cdot e_{1} \\
-\beta_{2} \cdot\left|e_{1}\right| \cdot \operatorname{sigmoid}\left(e_{1}\right)
\end{array}\right],
\end{aligned}
$$

where

$$
\operatorname{sigmoid}\left(e_{1}\right)=\left(\frac{2}{1+\exp \left(-a e_{1}\right)}\right)-1
$$

3.3. Proposed Adaptive Nonlinear ESO. Although a large $(R+$ $L \beta_{1}$ ) will render $e_{2}$ stable in a wider range, the steady-state error still has to be considered here. From (13) we know that a large $\left(R+L \beta_{1}\right)$ leads to the increase of $e_{2}$ in steady state. The improved method proposed in this paper is to adaptively adjust the parameters of NLESO to a compromised value which takes both stability and steady-state error into consideration.

Rewrite inequality (27) as the following expression:

$$
\frac{2 C}{B}>\frac{1}{R+L \beta_{1}} .
$$

Thus, the roots of (29) hold the following equality:

$$
\left|e_{2}\right|=\frac{2 C|h|}{B}>\frac{|h|}{R+L \beta_{1}} .
$$




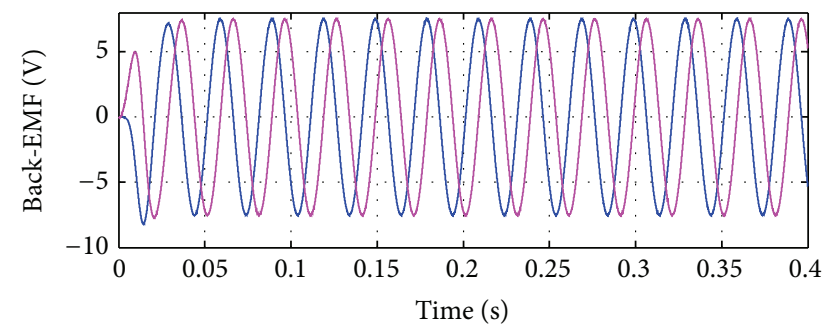

- Estimated $e_{\alpha}$

Estimated $e_{\beta}$

(a)

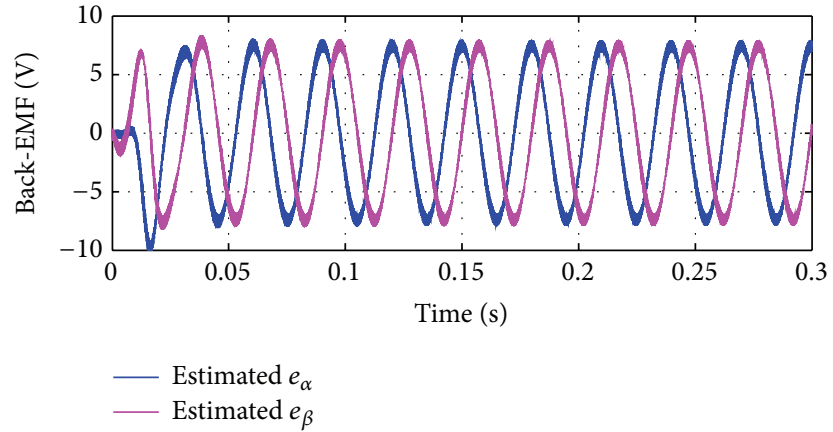

(b)

FIGURE 3: Simulation waveforms of estimated back EMF when speed is $500 \mathrm{r} / \mathrm{min}$ and the load torque is $1 \mathrm{Nm}$ : (a) obtained by the proposed ANLESO and (b) obtained by the conventional SMO.
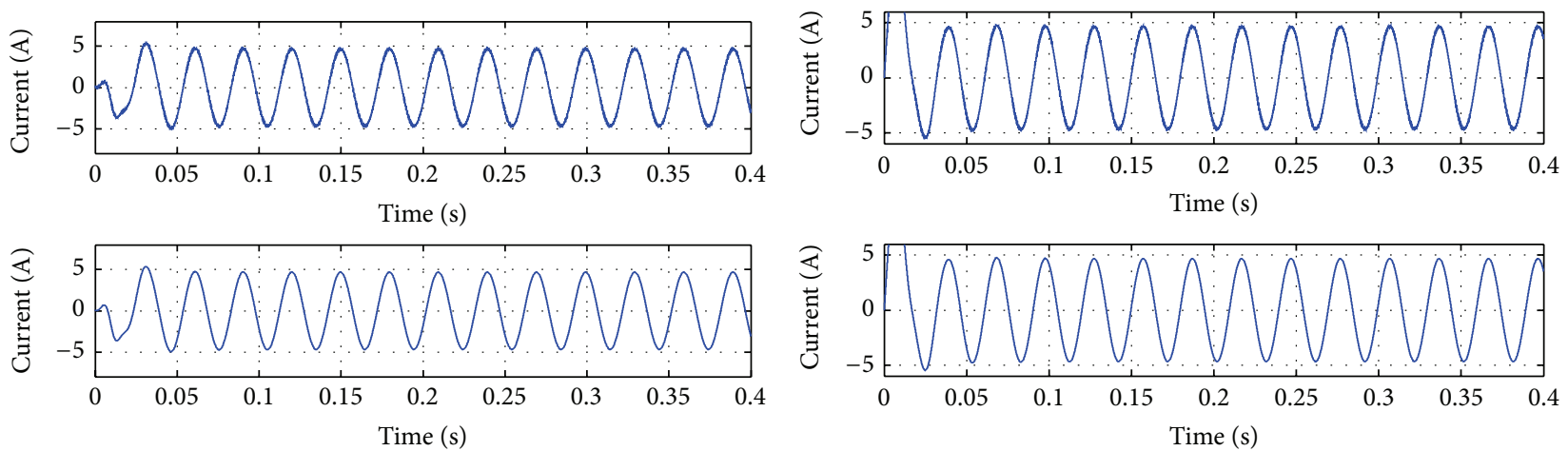

(a)
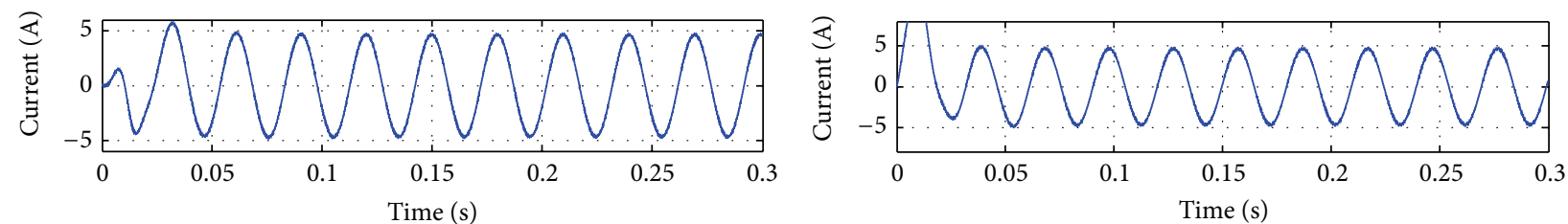

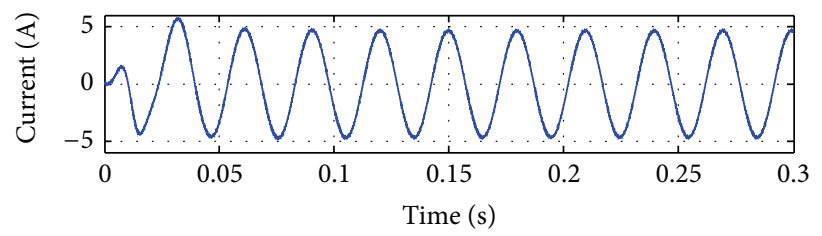

(c)

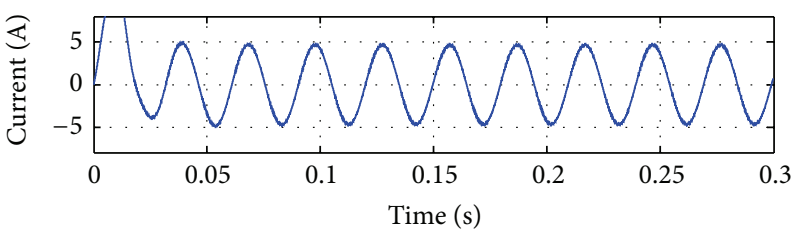

(d)

FIGURE 4: Simulation waveforms of actual and estimated $i_{\alpha}, i_{\beta}$ when speed is $500 \mathrm{r} / \mathrm{min}$ and the load torque is $1 \mathrm{Nm}$. (a) Actual and estimated $i_{\alpha}$ obtained by the proposed ANLESO. (b) Actual and estimated $i_{\beta}$ obtained by the proposed ANLESO. (c) Actual and estimated $i_{\alpha}$ obtained by the conventional SMO. (d) Actual and estimated $i_{\beta}$ obtained by the conventional SMO.

This means that the lower bound of $e_{2}$ is larger than $|h| /\left(R+L \beta_{1}\right) \cdot \beta_{1}$ is a design parameter, so the size of $R+L \beta_{1}$ can be changed by means of adjusting $\beta_{1}$. The main idea of this method is to decrease $\beta_{1}$ gradually to reduce steady-state error and increase $\beta_{1}$ when the system may become unstable. By several iterations, the value of $\beta_{1}$ would approximate the compromised value gradually.
Figure 2 illustrates the algorithm to calculate $\beta_{1}$, where $0<\alpha<1$ and $p>1$ are adjustment factors. $\Delta V$ is the error of command velocity and measured velocity.

3.4. Rotor Position and Speed Estimate. Using the estimated back-EMF obtained by the ANLESO, the position and speed 


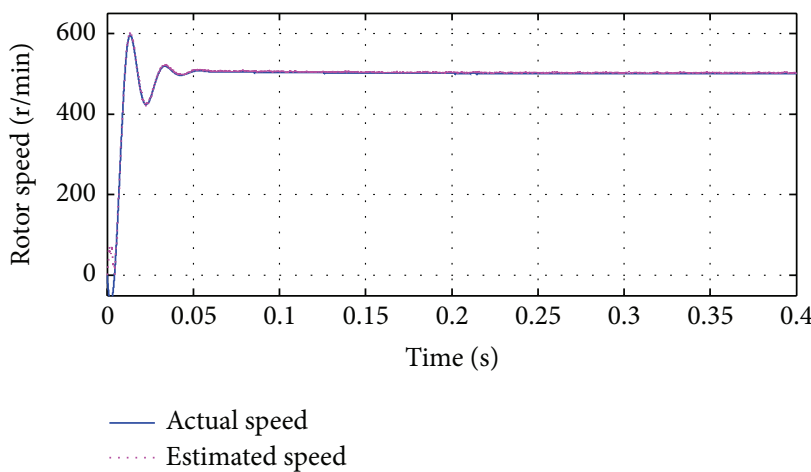

(a)

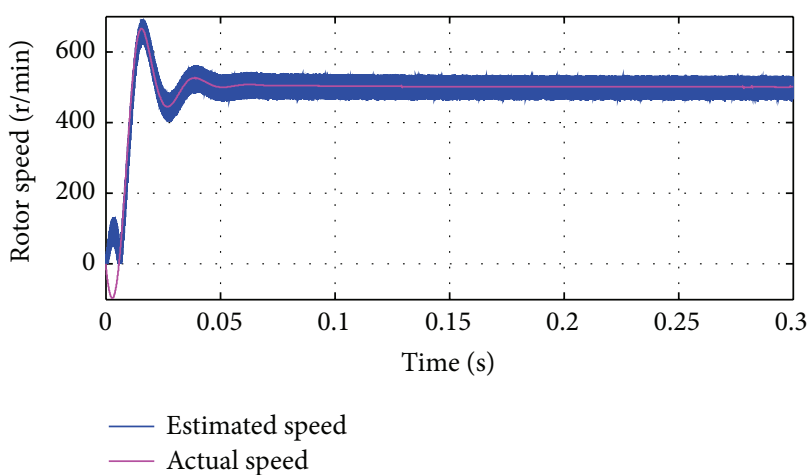

(b)

FIGURE 5: Simulation waveforms of actual and estimated speeds when speed is $500 \mathrm{r} / \mathrm{min}$ and the load torque is $1 \mathrm{Nm}$ : (a) obtained by the proposed ANLESO and (b) obtained by the conventional SMO.

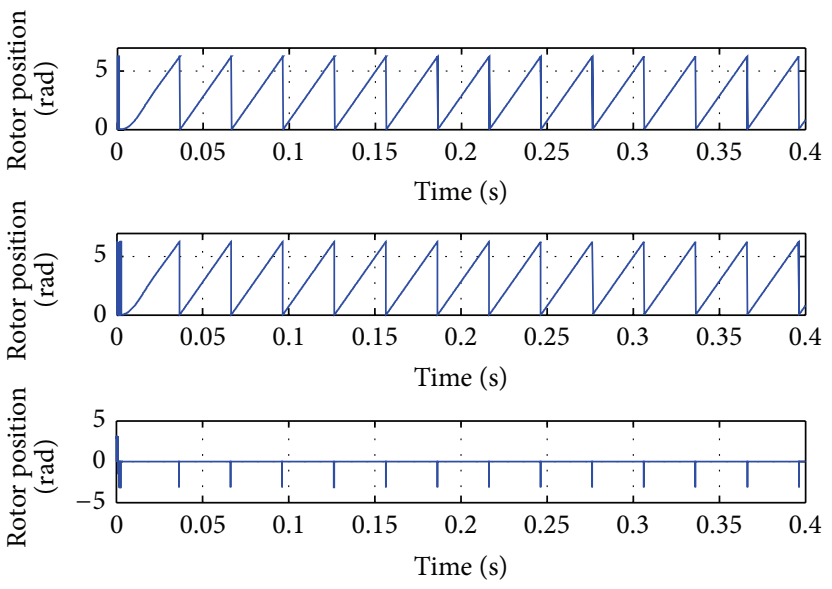

(a)

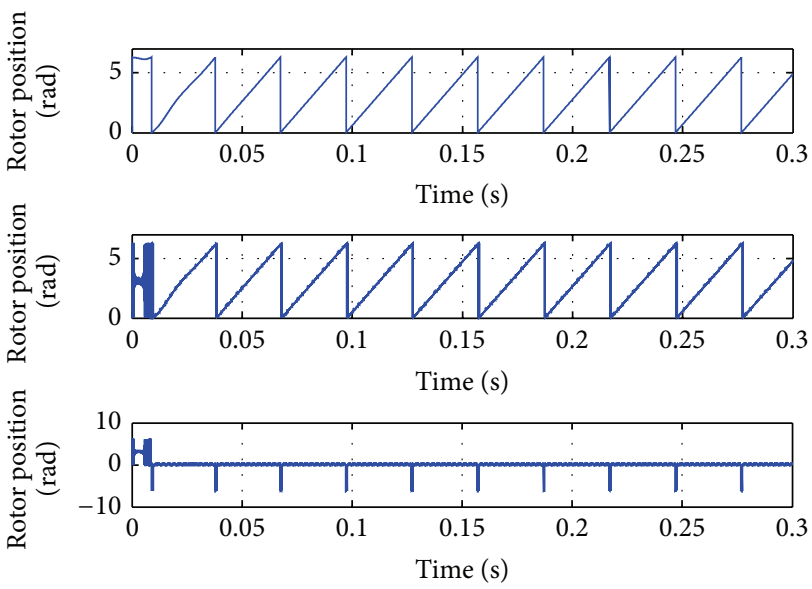

(b)

FIGURE 6: Simulation waveforms of actual rotor position, estimated rotor position, and estimated error when speed is $500 \mathrm{r} / \mathrm{min}$ and the load torque is $1 \mathrm{Nm}$ : (a) obtained by the proposed ANLESO and (b) obtained by the conventional SMO.

signals can be calculated easily. According to (3), the rotor speed can be obtained as follows:

$$
\widehat{\omega}_{r}=\frac{\sqrt{\left(\hat{e}_{\alpha}^{2}+\widehat{e}_{\beta}^{2}\right)}}{K_{E}} .
$$

Similarly, the rotor position can be deduced from (3) as follows:

$$
\widehat{\theta}=-\arctan \left[\frac{\widehat{e}_{\alpha}}{\widehat{e}_{\beta}}\right] .
$$

\section{Simulation and Experimental Results}

4.1. Simulation Results. In order to show the high-speed performance of the proposed ANLESO, it is necessary to compare it with the conventional SMO through the MatLab/Simulink programming environment. The parameters of PMSM used in simulation are listed in Table 1.

Figures 3-6 show the simulation waveforms when the reference speed is changed from zero to $500 \mathrm{r} / \mathrm{min}$ and
TABLE 1: The parameters of PMSM.

\begin{tabular}{lc}
\hline Parameters & Values \\
\hline Rated power & $1.5 \mathrm{KW}$ \\
Rated speed & $2500 \mathrm{r} / \mathrm{min}$ \\
Input voltage (DC) & $310 \mathrm{~V}$ \\
Current & $6 \mathrm{~A}$ \\
Stator resistance & $1.18 \Omega$ \\
Stator inductance & $53.26 \mathrm{mH}$ \\
Rotational inertia & $1.33 \times 10^{-3} \mathrm{~kg} \cdot \mathrm{m}^{2}$ \\
Flux of permanent magnet & $0.0356 \mathrm{~Wb}$ \\
Poles & 8 \\
\hline
\end{tabular}

the load torque is $1 \mathrm{Nm}$. In these figures, part (a) gives the simulation waveforms obtained by the proposed ANLESO and part (b) gives the simulation waveforms obtained by the conventional SMO. Estimated back-EMF, actual and estimated phase currents, actual and estimated rotor speed, 


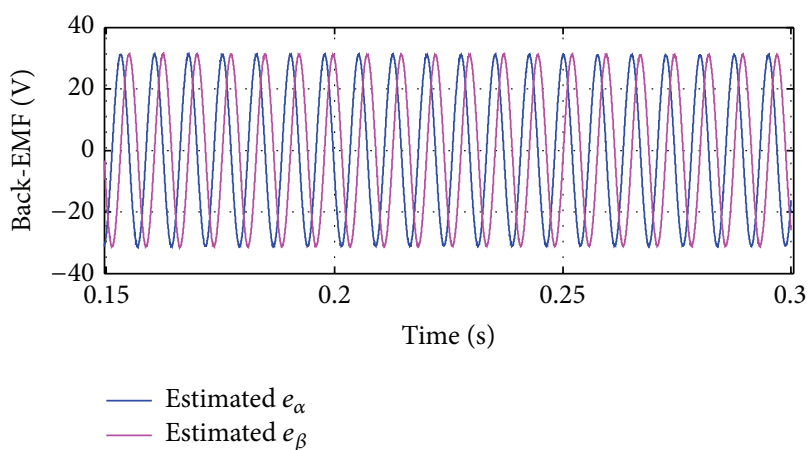

(a)

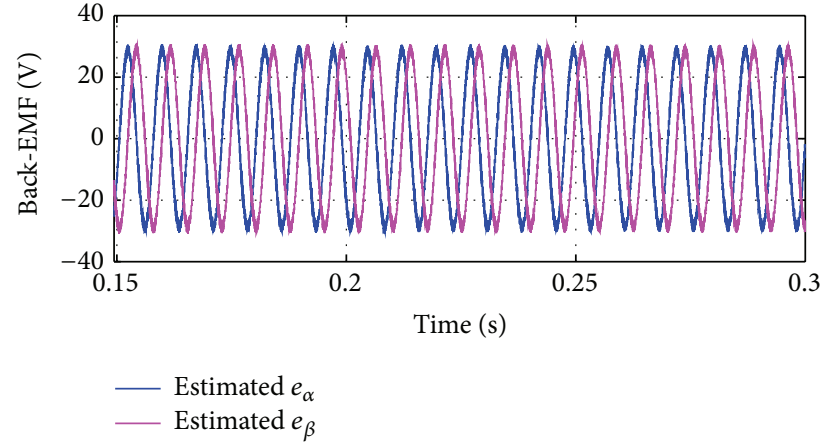

(b)

FIGURE 7: Simulation waveforms of estimated back EMF when speed is $2000 \mathrm{r} / \mathrm{min}$ and the load torque is $1 \mathrm{Nm}$ : (a) obtained by the proposed ANLESO and (b) obtained by the conventional SMO.
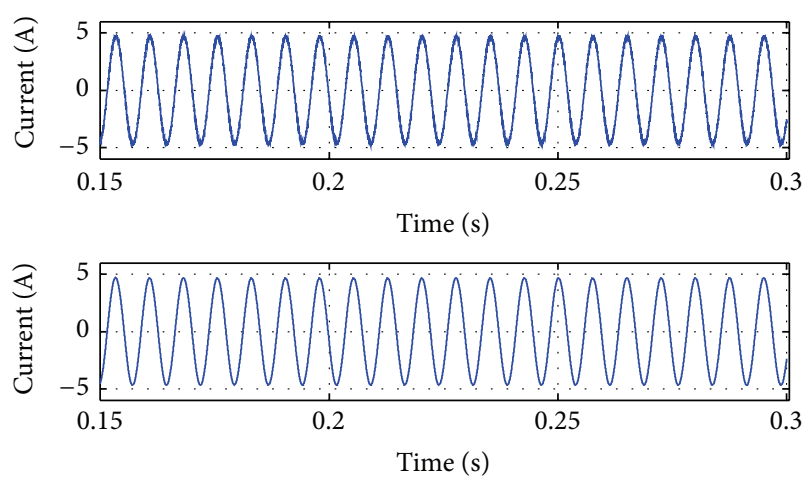

(a)
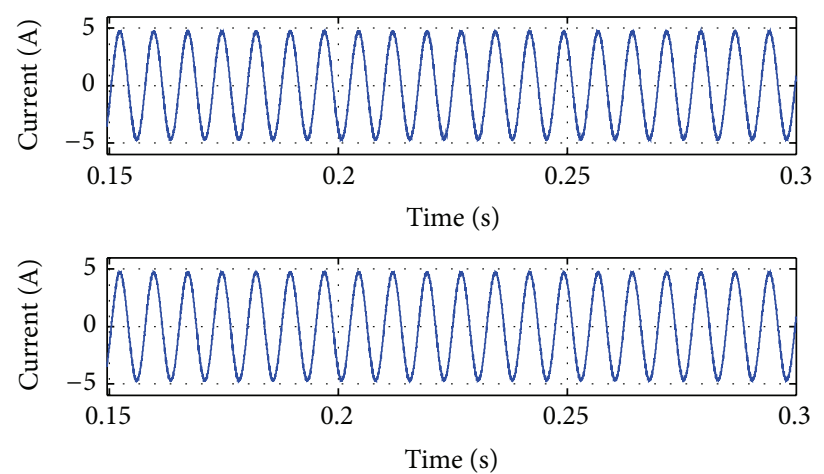

(c)
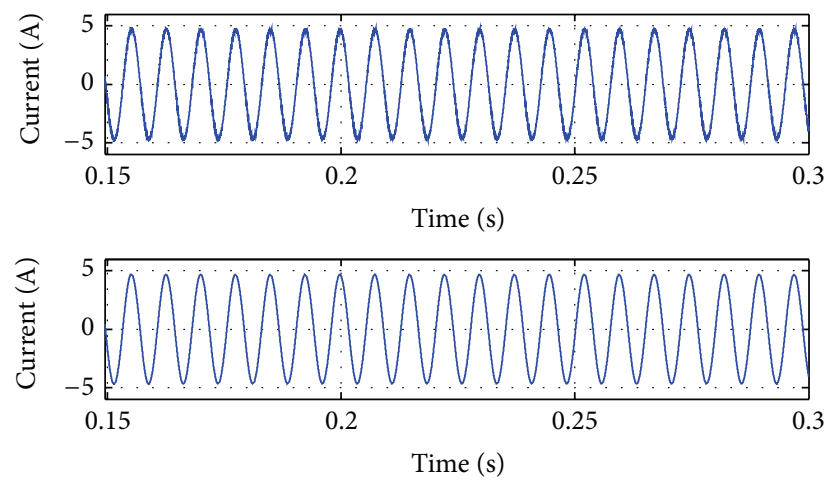

(b)
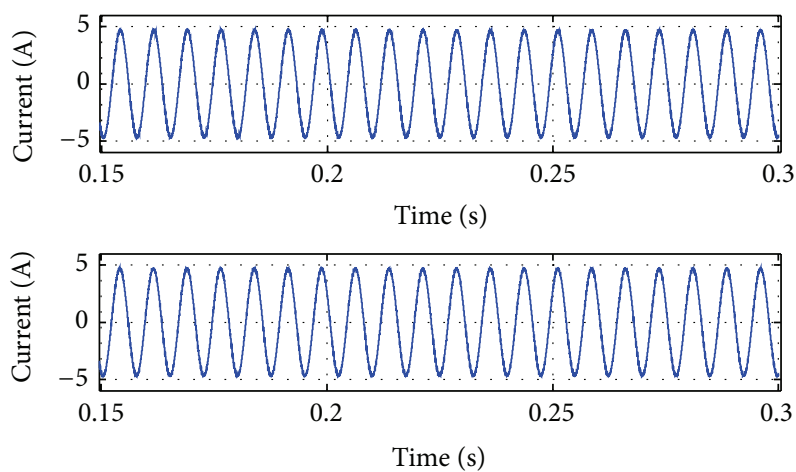

(d)

FIGURE 8: Simulation waveforms of actual and estimated $i_{\alpha}, i_{\beta}$ when speed is $2000 \mathrm{r} / \mathrm{min}$ and the load torque is $1 \mathrm{Nm}$. (a) Actual and estimated $i_{\alpha}$ obtained by the proposed ANLESO. (b) Actual and estimated $i_{\beta}$ obtained by the proposed ANLESO. (c) Actual and estimated $i_{\alpha}$ obtained by the conventional SMO. (d) Actual and estimated $i_{\beta}$ obtained by the conventional SMO.

and actual and estimated rotor position are also shown in these figures.

As can be seen from Figures 3-6, the accuracy of estimation has been greatly improved with the help of proposed ANLESO. Different from the conventional SMO, the backEMF in Figure 3(a) almost has no chattering. Compared with Figures 4(c) and 4(d), the estimated results of phase currents in Figures 4(a) and 4(b) are better. Due to the good performance of estimating back-EMF and currents, the chattering phenomenon of the estimated rotor position and speed is reduced, which can be seen from Figures 5(a), 5(b), 6(a), and 6(b). In part (a) of these figures, the estimated speed is almost the same as actual speed; however, the estimated speed in part (b) of these figures exhibits the chattering 


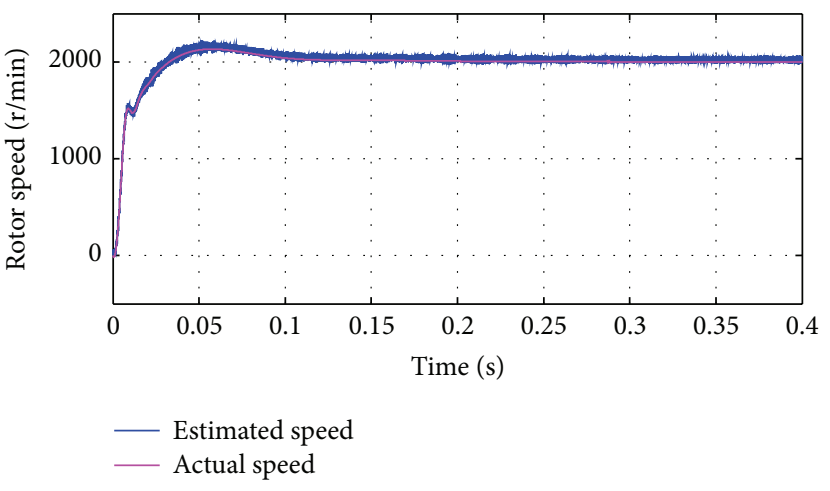

(a)

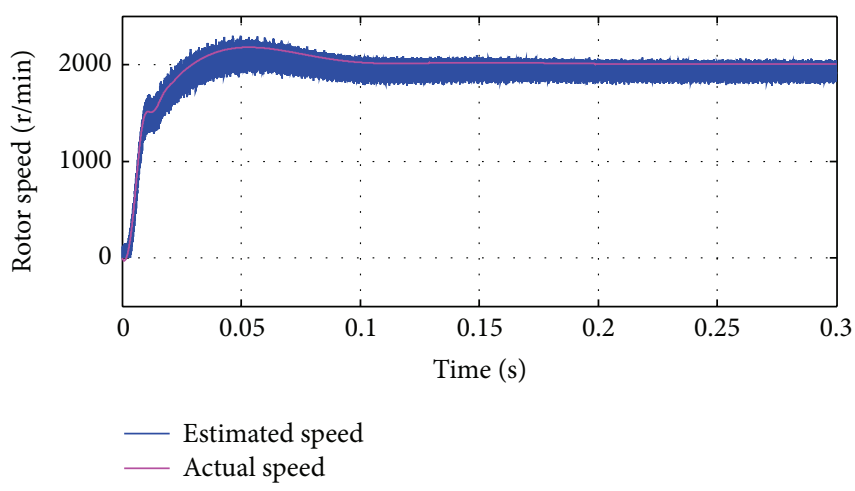

(b)

Figure 9: Simulation waveforms of actual and estimated speeds when speed is $2000 \mathrm{r} / \mathrm{min}$ and the load torque is $1 \mathrm{Nm}$ : (a) obtained by the proposed ANLESO and (b) obtained by the conventional SMO.

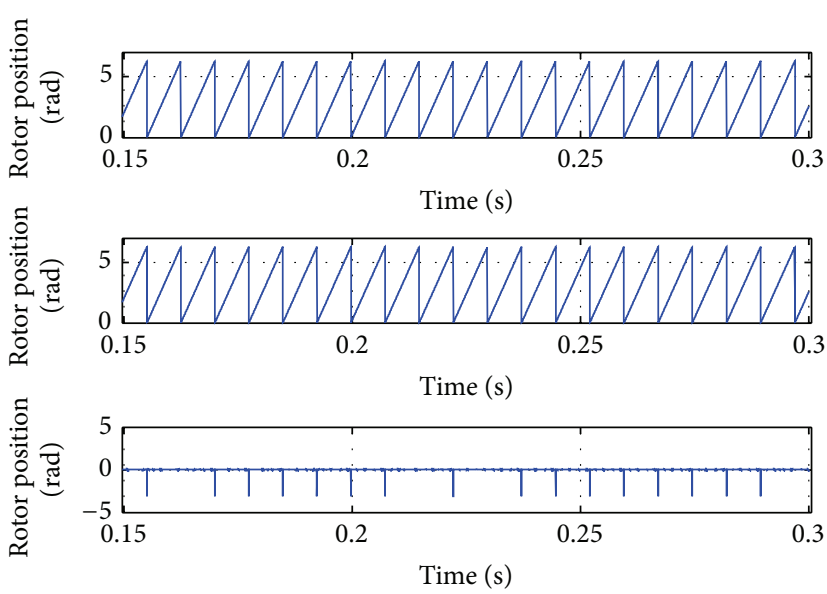

(a)
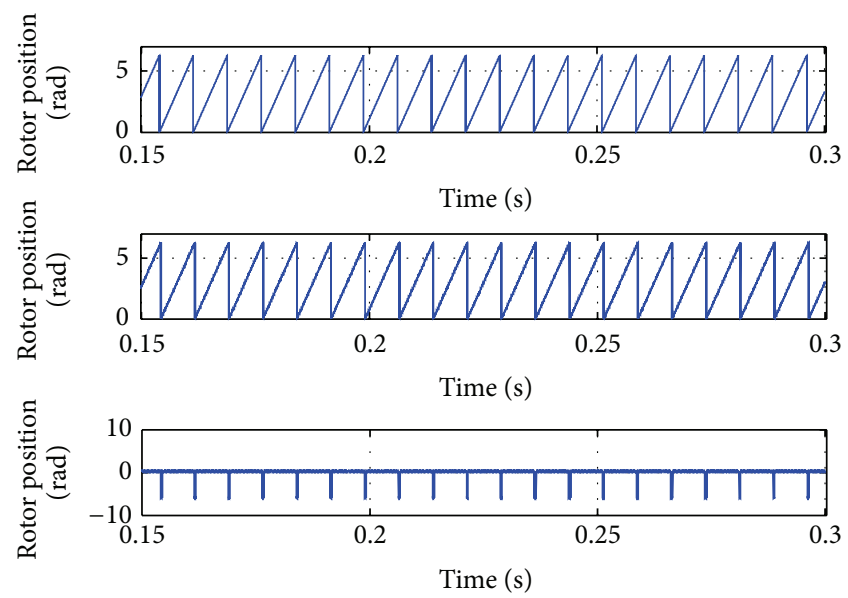

(b)

FIGURE 10: Simulation waveforms of actual rotor position, estimated rotor position, and estimated error when speed is $2000 \mathrm{r} / \mathrm{min}$ and the load torque is $1 \mathrm{Nm}$ : (a) obtained by the proposed ANLESO and (b) obtained by the conventional SMO.

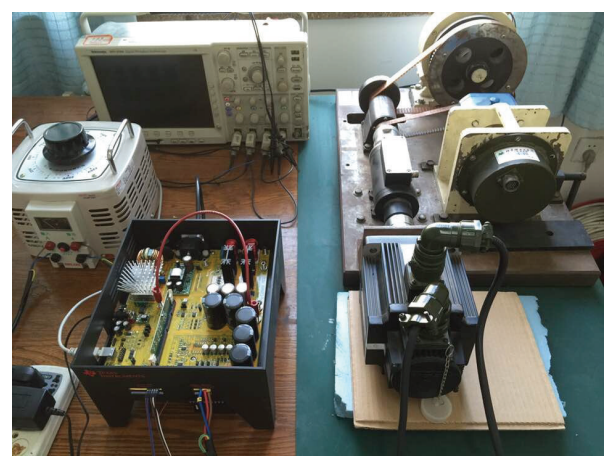

FIGURE 11: Platform of 1.5 kw PMSM sensorless control system based on DSP.

phenomenon. Besides, it can be seen that the estimated error of the position in part (a) is smaller than that shown in part (b) of these figures.

Figures 7-10 show the two sets of simulation waveforms when the reference speed is changed from zero to $2000 \mathrm{r} / \mathrm{min}$ and the load torque is $1 \mathrm{Nm}$. In these figures, part (a) gives the simulation waveforms obtained by the proposed ANLESO and part (b) gives the simulation waveforms obtained by the conventional SMO. Estimated back-EMF, actual and estimated phase currents, actual and estimated rotor speed, 


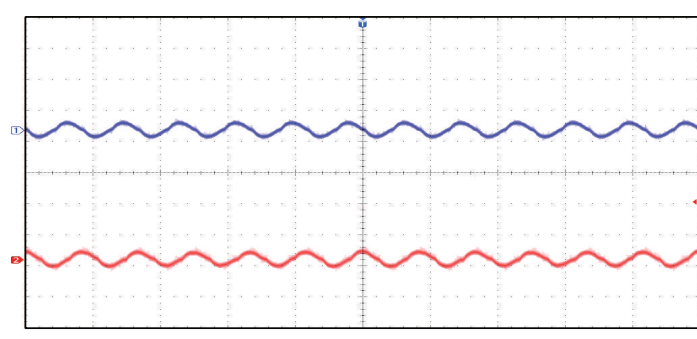

(a)

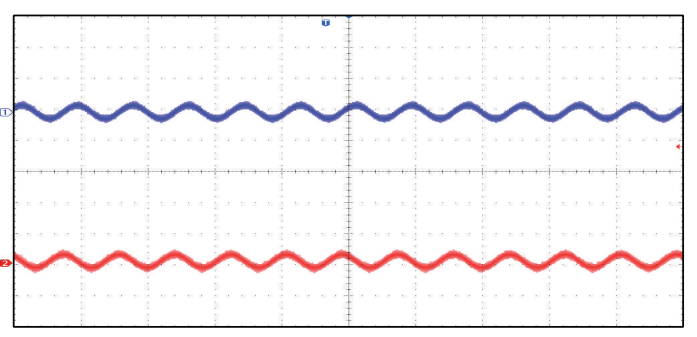

(b)

FIGURE 12: Operating waveforms of estimated back EMF in steady state when speed is $500 \mathrm{r} / \mathrm{min}$ and the load torque is $1 \mathrm{Nm}$ : (a) obtained by the proposed ANLESO and (b) obtained by the conventional SMO.

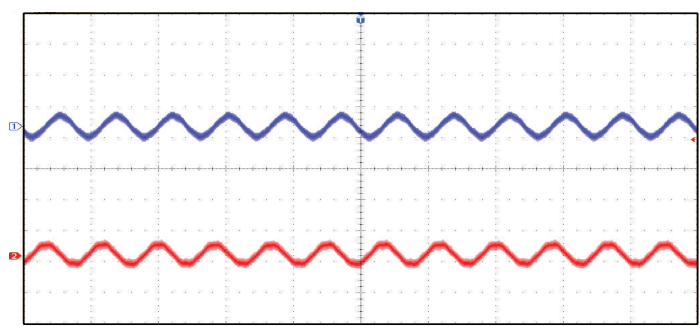

(a)

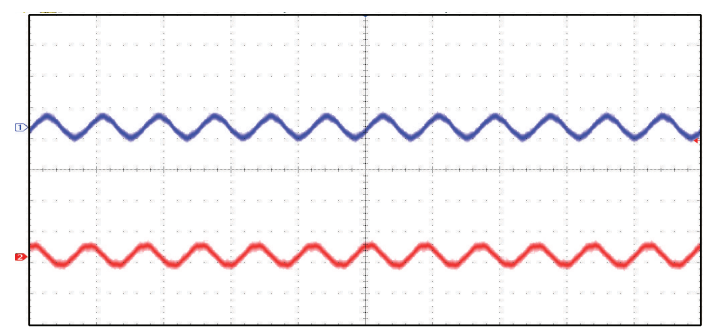

(b)

FIGURE 13: Operating waveforms of estimated $i_{\alpha}$ and $i_{\beta}$ in steady state when speed is $500 \mathrm{r} / \mathrm{min}$ and the load torque is $1 \mathrm{Nm}$ : (a) obtained by the proposed ANLESO and (b) obtained by the conventional SMO.

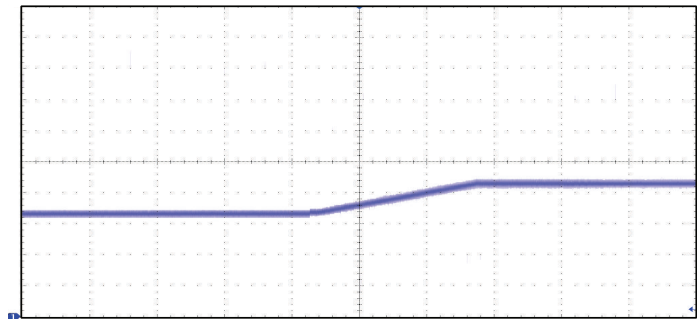

(a)

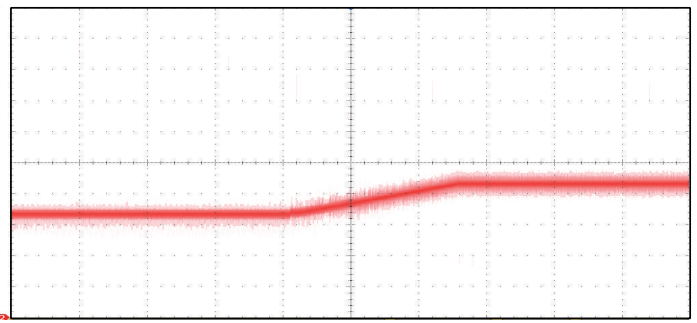

(b)

FIGURE 14: Operating waveforms of estimated rotor speeds when speed is $500 \mathrm{r} / \mathrm{min}$ and the load torque is $1 \mathrm{Nm}$ : (a) obtained by the proposed ANLESO and (b) obtained by the conventional SMO.

and actual and estimated rotor position are also shown in these figures.

As can be seen from Figures 7-10, when the rotor speed is raised to $2000 \mathrm{r} / \mathrm{min}$, advantages of ANLESO become more apparent than conventional SMO. Comparing the estimated back-EMF in Figures 7(a) and 7(b), we can find that the former has smaller chattering. As a result, the estimation of rotor speed becomes more accurate by ANLESO, which can be seen in Figures 9(a) and 9(b). The waveform forms presented in Figures 10(a) and 10(b) show the estimated rotor position. The position estimation error is reduced and the accuracy of rotor position estimation is improved in Figure 10(a).

4.2. Experimental Results. To further verify the performance of the new SMO for estimating rotor position and speed, an experimental system has been designed to control the 130SJTM060D (1.5 kw) sinusoidal PMSM motor made by GSK.

Figure 11 shows a photograph of the sensorless control system. The High Voltage Digital Motor Control Kit, made by TI, is utilized in the system, which contains power modules, switching devices, current and voltage sensing circuit, ADC modules, and PWM DAC (digital to analog converter) modules. A floating-point TMS320F28335 DSP is employed as the digital controller. The current control cycle is $100 \mu \mathrm{s}$ and the velocity control cycle is $1 \mathrm{~ms}$. A $2 \mu$ s dead time is chosen for the PWM switching. All of the control variables are monitored in real time by an oscilloscope after they are converted to analog signals through the PWM DACs modules, which use an external low pass filter to generate the waveforms. The motor parameters used in experiment are given in Table 1. 


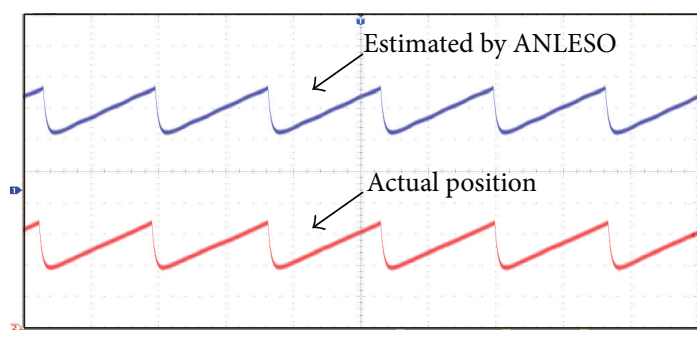

(a)

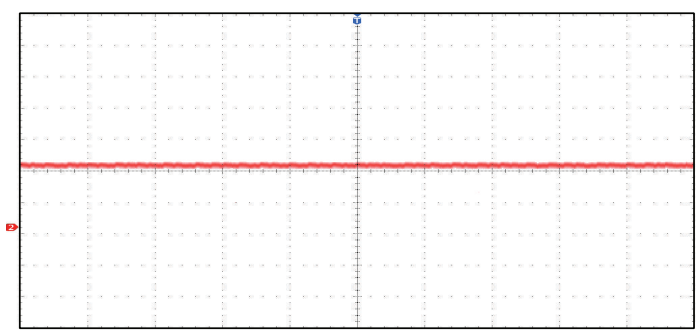

(c)

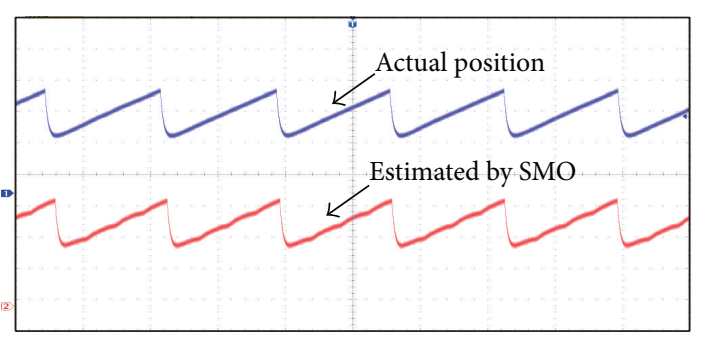

(b)

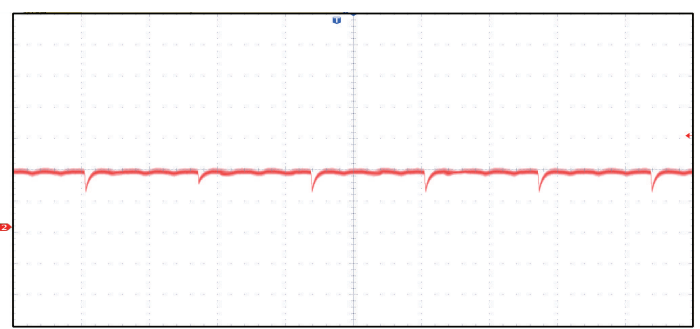

(d)

FIGURE 15: Operating waveforms of rotor position and estimate error when speed is $500 \mathrm{r} / \mathrm{min}$ and the load torque is $1 \mathrm{Nm}$. (a) Actual and estimated rotor position obtained by the proposed ANLESO. (b) Actual and estimated rotor position obtained by the conventional SMO. (c) Estimated error obtained by the proposed ANLESO. (d) Estimated error obtained by the conventional SMO.

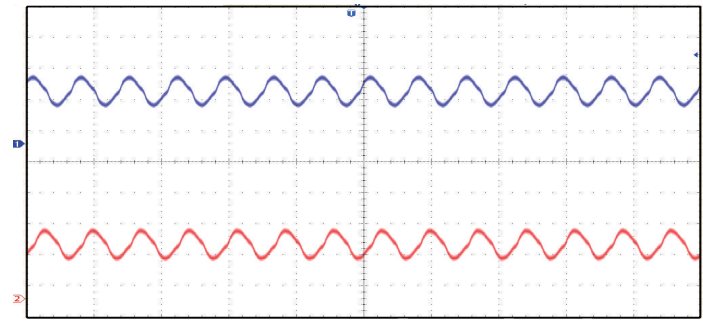

(a)

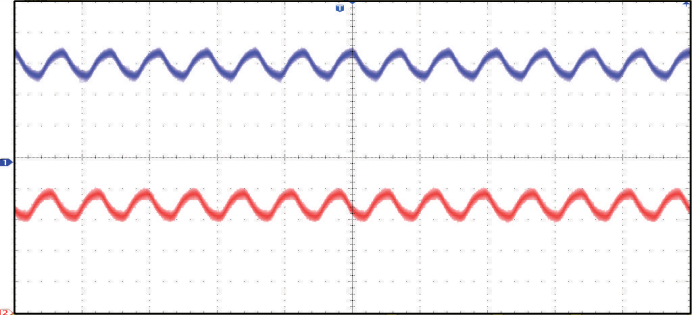

(b)

Figure 16: Operating waveforms of estimated back EMF in steady state when speed is $2000 \mathrm{r} / \mathrm{min}$ and the load torque is $1 \mathrm{Nm}$ : (a) obtained by the proposed ANLESO and (b) obtained by the conventional SMO.

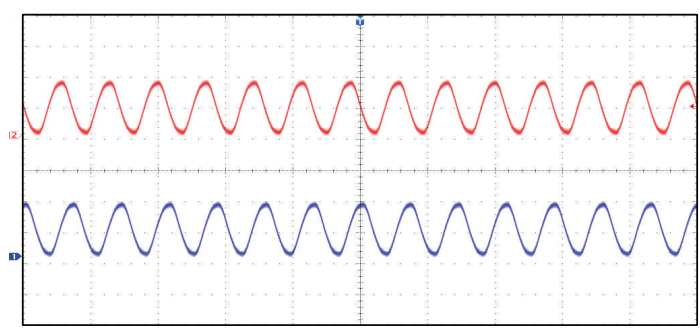

(a)

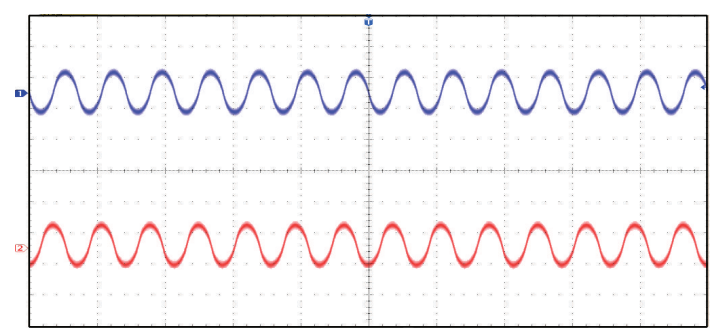

(b)

FiguRE 17: Operating waveforms of estimated $i_{\alpha}$ and $i_{\beta}$ in steady state when speed is $2000 \mathrm{r} / \mathrm{min}$ and the load torque is $1 \mathrm{Nm}$ : (a) obtained by the proposed ANLESO and (b) obtained by the conventional SMO.

Figures 12-14 show the operating waveforms when the reference speed is changed from zero to $500 \mathrm{r} / \mathrm{min}$ and the load torque is $1 \mathrm{Nm}$. In these figures, part (a) gives the operating waveforms obtained by the proposed ANLESO and part (b) gives the operating waveforms obtained by the conventional SMO. Estimated back-EMF, estimated phase currents, and estimated rotor speed are shown in these figures. In Figure 15, actual rotor position, estimated rotor position, and their error are shown.

Figures 12(a) and 13(a) show the experimental results of the proposed ANLESO. Compared to the waveforms obtained by SMO (see part (b) in Figures 12 and 13), 


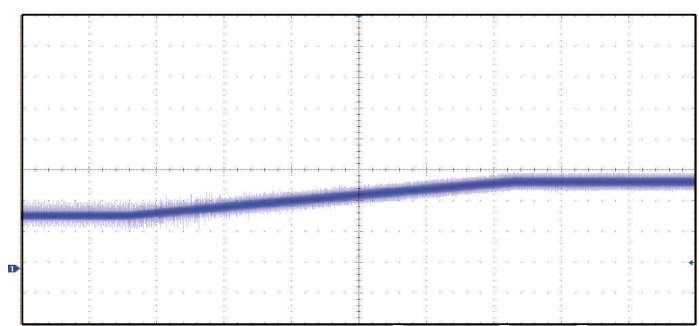

(a)

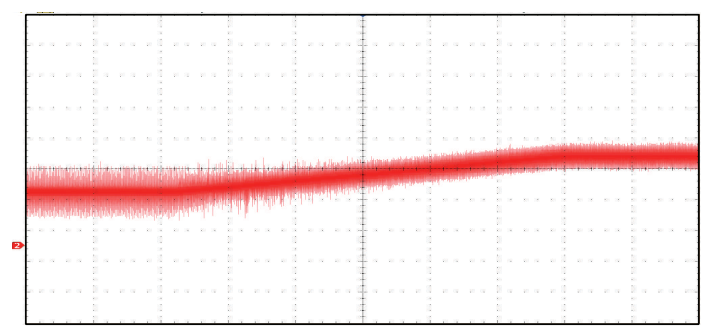

(b)

FIGURE 18: Operating waveforms of estimated rotor speeds when speed is $2000 \mathrm{r} / \mathrm{min}$ and the load torque is $1 \mathrm{Nm}$ : (a) obtained by the proposed ANLESO and (b) obtained by the conventional SMO.

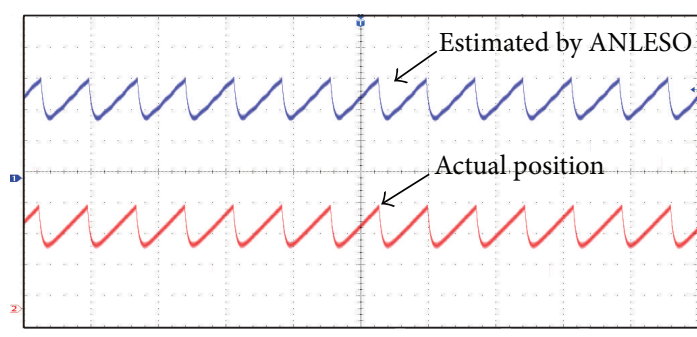

(a)

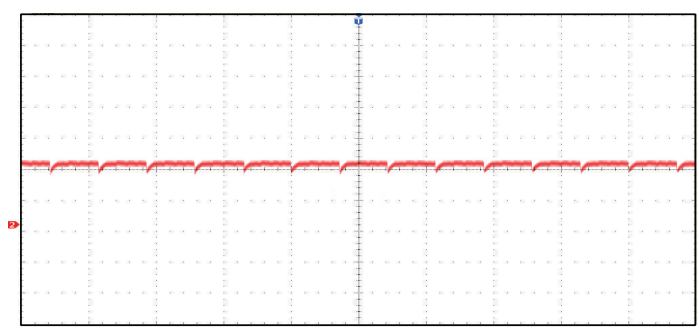

(c)

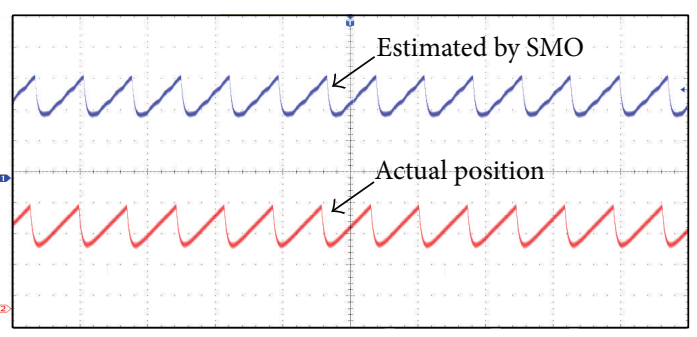

(b)

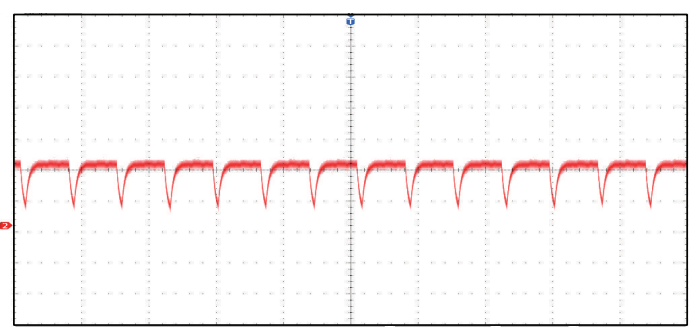

(d)

FIGURE 19: Operating waveforms of rotor position and estimate error when speed is $2000 \mathrm{r} / \mathrm{min}$ and the load torque is $1 \mathrm{Nm}$. (a) Actual and estimated rotor position obtained by the proposed ANLESO. (b) Actual and estimated rotor position obtained by the conventional SMO. (c) Estimated error obtained by the proposed ANLESO. (d) Estimated error obtained by the conventional SMO.

the waveforms of the estimated back-EMF and current shown in Figures 12(a) and 13(a) are more accurate. The waveforms presented in Figures 14(a) and 14(b) show the differences of rotor speed estimated by two kinds of observers. The former speed waveform has less chattering. In other words, ANLESO has higher estimated precision.

Figure 15 shows the experimental results of position response. The estimated error shown in Figure 15(c) is smaller than that in Figure 15(d), which verifies the high precision of ANLESO.

Figures 16-18 show the operating waveforms when the reference speed is changed from zero to $2000 \mathrm{r} / \mathrm{min}$ and the load torque is $1 \mathrm{Nm}$. In these figures, part (a) gives the operating waveforms obtained by the proposed ANLESO and part (b) gives the operating waveforms obtained by the conventional SMO. In these figures, estimated back-EMF, estimated phase currents, and estimated rotor speed are shown. In Figure 19, actual rotor position, estimated rotor position, and their error are shown.
Figures 12-15 show the operating waveforms when the reference speed is changed from zero to $2000 \mathrm{r} / \mathrm{min}$. Figures 12 and 13 provide the operating waveforms obtained by the proposed ANLESO. Figures 14 and 15 show the simulation waveforms obtained by the conventional SMO. In these figures, estimated back-EMF, estimated phase currents, estimated rotor speed, and actual and estimated rotor position are shown.

Figures 16-18 show the experimental results of estimated back-EMF, current and rotor speed when the rotor speed is raised to $2000 \mathrm{r} / \mathrm{min}$. It can be seen that the waveforms in part (a) of these figures have smaller chattering and higher accuracy. In this way, the advantages of ANLESO have been verified.

As shown in Figure 19, when the rotor speed is raised to $2000 \mathrm{r} / \mathrm{min}$, the advantages of ANLESO to estimate rotor position become more apparent than conventional SMO. The estimation error in Figure 19(c) is significantly less than that in Figure 19(d). That is to say, ANLESO has higher accuracy 
and smaller chattering when being applied to estimate position than SMO.

\section{Conclusions}

In this paper, an adaptive nonlinear extended state observer has been designed for the sensorless control of a PMSM. The convergence of this observer has been proved by means of a Lyapunov stability analysis. An adaptive algorithm is adopted to calculate the compromised parameter of ESO in order to take both stability and steady-state error into consideration. The good performance of the proposed sensorless control system was verified by several experimental results. The results show that ANLESO has more advantages than conventional SMO. Compared to conventional SMO, ANLESO has smaller chattering, higher accuracy, and no phase delay.

In future works, we will explore the stability of the ESO under parameter uncertainties in sensorless control system.

\section{Conflict of Interests}

The authors declare that there is no conflict of interests regarding the publication of this paper.

\section{Acknowledgments}

This project was supported by the National Natural Science Foundation of China (Grant no. 61304097) and Projects of Major International (Regional) Joint Research Program NSFC (Grant no. 61120106010).

\section{References}

[1] S. Lu, X. Tang, and B. Song, "Adaptive PIF control for permanent magnet synchronous motors based on GPC," Sensors, vol. 13, no. 1, pp. 175-192, 2013.

[2] A. Gómez-Espinosa, V. M. Hernández-Guzmán, M. BandalaSánchez et al., "A new adaptive self-tuning Fourier Coefficients algorithm for periodic torque ripple minimization in permanent magnet synchronous motors (PMSM)," Sensors, vol. 13, no. 3, pp. 3831-3847, 2013.

[3] Y. Zhang, C. M. Akujuobi, W. H. Ali, C. L. Tolliver, and L.-S. Shieh, "Load disturbance resistance speed controller design for PMSM," IEEE Transactions on Industrial Electronics, vol. 53, no. 4, pp. 1198-1208, 2006.

[4] J. C. Gamazo-Real, E. Vázquez-Sánchez, and J. Gómez-Gil, "Position and speed control of brushless DC motors using sensorless techniques and application trends," Sensors, vol. 10, no. 7, pp. 6901-6947, 2010.

[5] J.-H. Jang, S.-K. Sul, J.-I. Ha, K. Ide, and M. Sawamura, "Sensorless drive of surface-mounted permanent-magnet motor by high-frequency signal injection based on magnetic saliency," IEEE Transactions on Industry Applications, vol. 39, no. 4, pp. 1031-1039, 2003.

[6] A. Piippo, M. Hinkkanen, and J. Luomi, "Sensorless control of PMSM drives using a combination of voltage model and HF signal injection," in Proceedings of the 39th IAS Annual Meeting, Conference Record of the IEEE Industry Applications Conference, vol. 2, pp. 964-970, October 2004.
[7] G. Wang, R. Yang, and D. Xu, "DSP-based control of sensorless IPMSM drives for wide-speed-range operation," IEEE Transactions on Industrial Electronics, vol. 60, no. 2, pp. 720-727, 2013.

[8] Z. Wang, Y. Zheng, Z. Zou, and M. Cheng, "Position sensorless control of interleaved CSI fed PMSM drive with extended Kalman filter," IEEE Transactions on Magnetics, vol. 48, no. 11, pp. 3688-3691, 2012.

[9] T. D. Batzel and K. Y. Lee, "An approach to sensorless operation of the permanent-magnet synchronous motor using diagonally recurrent neural networks," IEEE Transactions on Energy Conversion, vol. 18, no. 1, pp. 100-106, 2003.

[10] B. Zhang and Y. Li, "A PMSM sliding mode control system based on model reference adaptive control," in Proceedings of the $3 \mathrm{rd}$ International Power Electronics and Motion Control Conference (IPEMC '00), vol. 1, pp. 336-341, IEEE, Beijing, China, 2000.

[11] S. Shinnaka, "New sensorless vector control using minimumorder flux state observer in a stationary reference frame for permanent-magnet synchronous motors," IEEE Transactions on Industrial Electronics, vol. 53, no. 2, pp. 388-398, 2006.

[12] A. Khlaief, M. Bendjedia, M. Boussak, and M. Gossa, "A nonlinear observer for high-performance sensorless speed control of IPMSM drive," IEEE Transactions on Power Electronics, vol. 27, no. 6, pp. 3028-3040, 2012.

[13] H. Lee and J. Lee, "Design of iterative sliding mode observer for sensorless PMSM control," IEEE Transactions on Control Systems Technology, vol. 21, no. 4, pp. 1394-1399, 2013.

[14] Y.-S. Han, J.-S. Choi, and Y.-S. Kim, "Sensorless PMSM drive with a sliding mode control based adaptive speed and stator resistance estimator," IEEE Transactions on Magnetics, vol. 36, no. 5, pp. 3588-3591, 2000.

[15] V. C. Ilioudis and N. I. Margaris, "PMSM sensorless speed estimation based on sliding mode observers," in Proceedings of the IEEE Power Electronics Specialists Conference (PESC '08), pp. 2838-2843, IEEE, Rhodes, Greece, June 2008.

[16] Z. Qiao, T. Shi, Y. Wang, Y. Yan, C. Xia, and X. He, "New slidingmode observer for position sensorless control of permanentmagnet synchronous motor," IEEE Transactions on Industrial Electronics, vol. 60, no. 2, pp. 710-719, 2013.

[17] Y. Huang and J. Han, "Analysis and design for the second order nonlinear continuous extended states observer," Chinese Science Bulletin, vol. 45, no. 21, pp. 1938-1944, 2000.

[18] J. Han, "From PID to active disturbance rejection control," IEEE Transactions on Industrial Electronics, vol. 56, no. 3, pp. 900906, 2009.

[19] Z. Gao, "Scaling and bandwidth-parameterization based controller tuning," in Proceedings of the American Control Conference, vol. 6, pp. 4989-4996, IEEE, June 2003.

[20] Y. Xia, Z. Zhu, and M. Fu, "Back-stepping sliding mode control for missile systems based on an extended state observer," IET Control Theory and Applications, vol. 5, no. 1, pp. 93-102, 2011.

[21] X. Li and S. Li, "Extended state observer based adaptive control scheme for PMSM system," in Proceedings of the 33rd IEEE Chinese Control Conference (CCC '14), 2014.

[22] B.-Z. Guo and Z.-L. Zhao, "On convergence of non-linear extended state observer for multi-input multi-output systems with uncertainty," IET Control Theory \& Applications, vol. 6, no. 15, pp. 2375-2386, 2012. 
[23] G. Zhu, A. Kaddouri, L. A. Dessaint, and O. Akhrif, "A nonlinear state observer for the sensorless control of a permanent-magnet AC machine," IEEE Transactions on Industrial Electronics, vol. 45, no. 2, pp. 291-296, 1996.

[24] J. Han, Active Disturbance Rejection Control Technique-The Technique for Estimating and Compensating the Uncertainties, National Defense Industry Press, Beijing, China, 2013, (Chinese). 


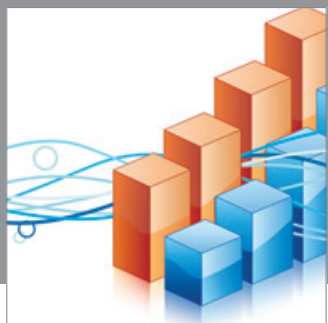

Advances in

Operations Research

mansans

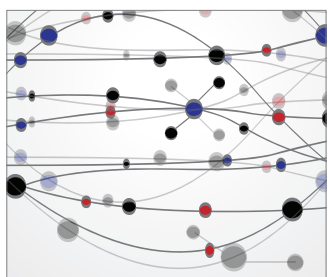

The Scientific World Journal
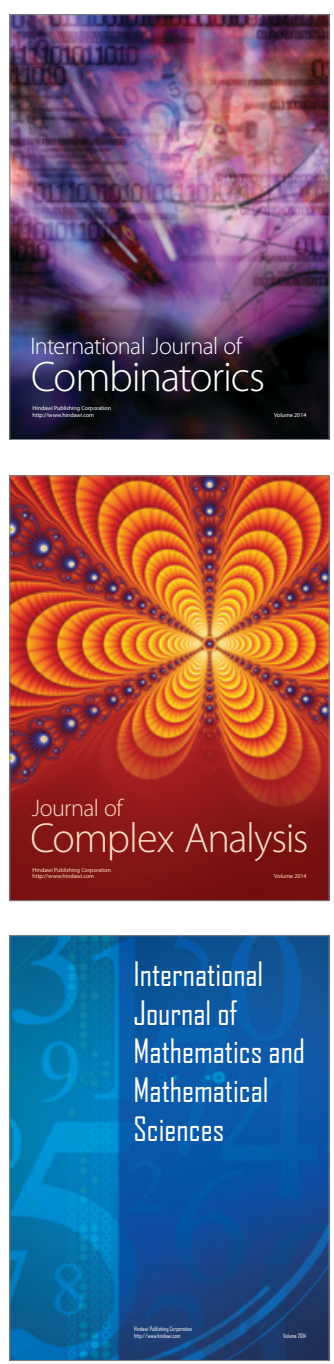
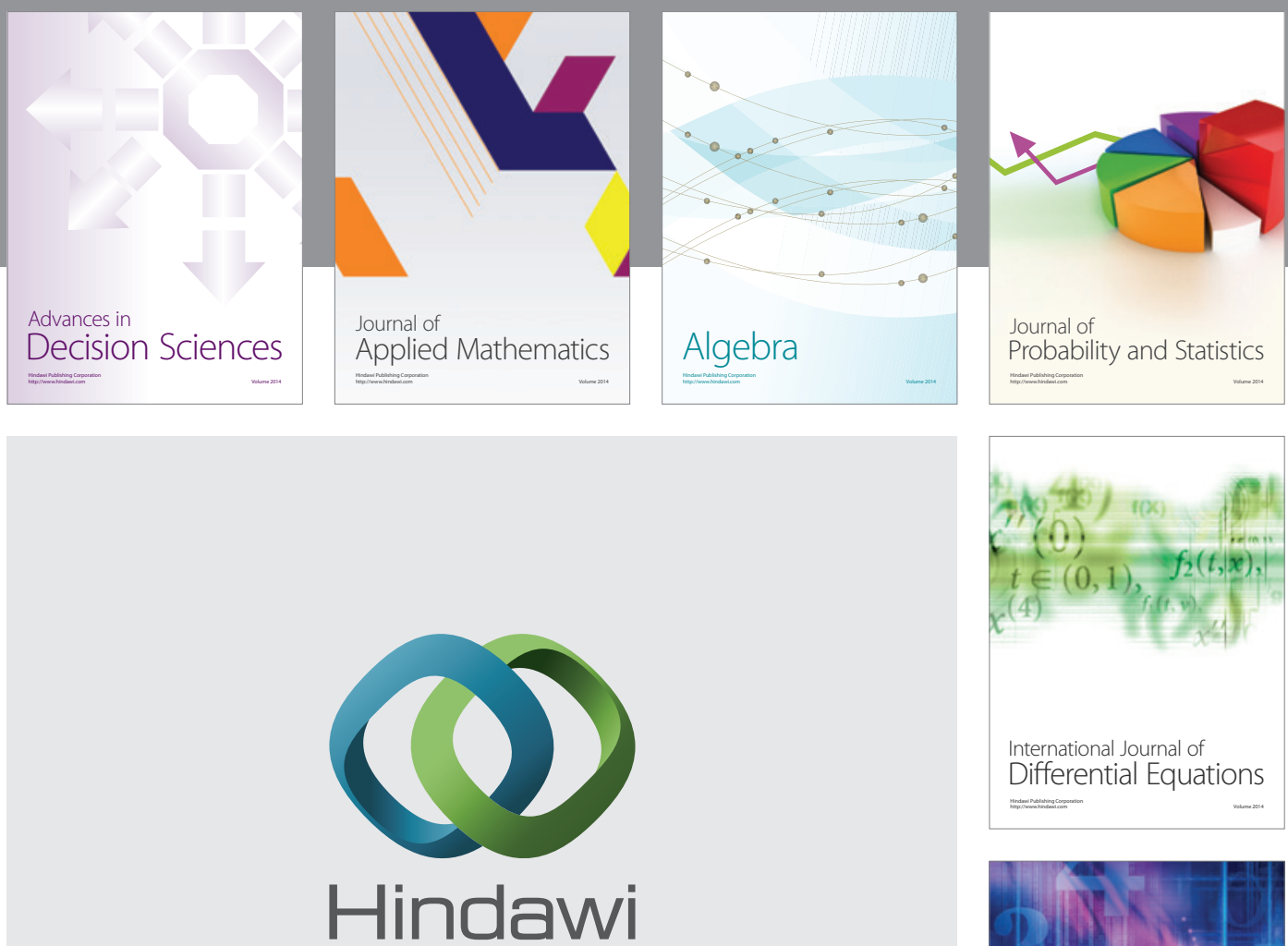

Submit your manuscripts at http://www.hindawi.com
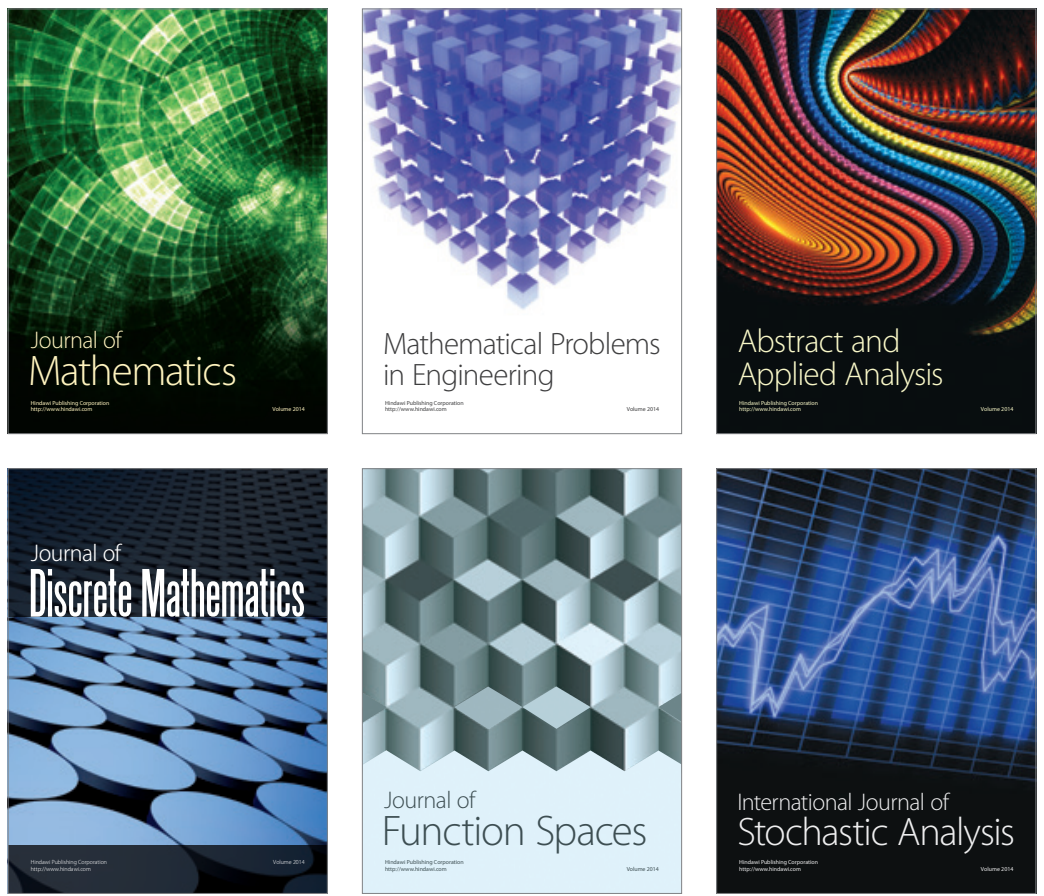

Journal of

Function Spaces

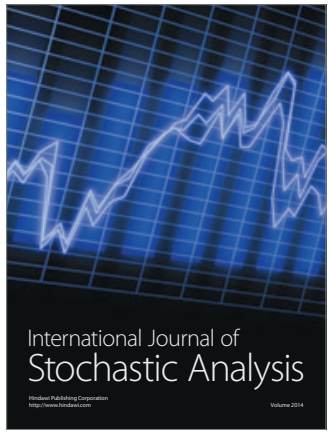

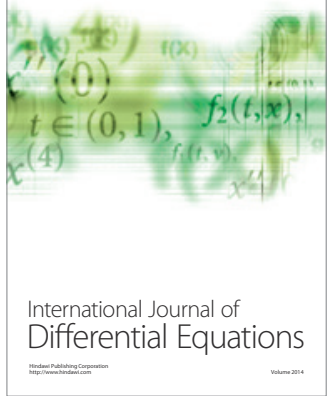
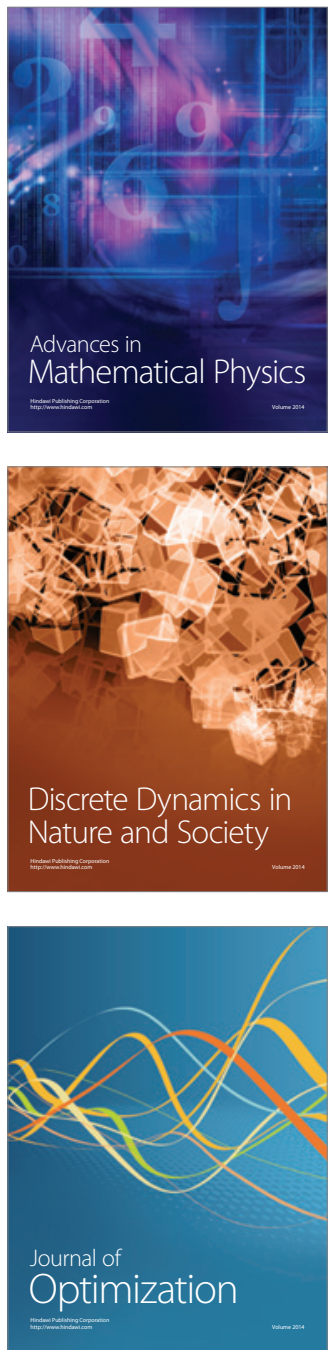